\title{
KANT'S ARGUMENT FOR THE PRINCIPLE OF ANTICIPATIONS OF PERCEPTION
}

\author{
WEIJIA WANG
}

\section{INTRODUCTION}

In the Critique of Pure Reason, Kant presents the Principle of Anticipations of Perception (PAP) as follows: "In all appearances the real, which is an object of the sensation, has intensive magnitude, i.e., a degree." (B207) ${ }^{1}$ As a principle of the pure understanding, the PAP is the rule of the "objective use" of the qualitative categories and thus claims a priori necessity (A161/B200). Since a sensation represents the real of an object and has in itself no space or time (B208), its apprehension is not successive but "instantaneous" (A169/B210). The PAP anticipates a priori the "synthesis of the generation of the magnitude of a sensation" and "a continuous nexus of possible realities" (B208). Kant defines "continuity" of magnitudes as their property of having no smallest part and claims that all appearances are continuous magnitudes (A169/B211-A171/

\footnotetext{
${ }^{1}$ Kant's works are cited by abbreviation and volume and page number from Immanuel Kants gesammelten Schriften, Ausgabe der königlich preußischen Akademie der Wissenschaften (Berlin, Germany: Walter de Gruyter, 1902 -). Abbreviations: DfS = Die falsche Spitzfindigkeit der vier syllogistischen Figuren; JL = Jäsche Logik; KU = Kritik der Urteilskraft; $\mathrm{MV}=$ Metaphysik Vigilantius; $\mathrm{NG}=$ Versuch den Begriff der negativen Größen in die Weltweisheit einzuführen; Pro $=$ Prolegomena zu einer jeden künftigen Metaphysik; $\mathrm{R}=$ Reflexionen $; \mathrm{UD}=$ Untersuchung über die Deutlichkeit der Grundsätze der natürlichen Theologie und der Moral. References to the Critique of Pure Reason are to the standard A and B pagination of the first and second editions. Unless otherwise specified, translations used are from the Cambridge Edition of the Works of Immanuel Kant (Cambridge: Cambridge UP: 1992 -), sometimes modified. I replace bold in the translations with italics.
} 
B212). On this basis, in a later section Kant states that all appearances change continuously in their states (A208/B253-A211/B256).

The stakes involved in the PAP are high indeed, since they amount to the justification of the law of continuity in nature. Commentators see many difficulties in Kant's theory, which can be categorized into three groups: first, some commentators $^{2}$ contend that Kant fails to derive the PAP from the qualitative categories and their schemata, such that his claims are unconvincing. Second, in some of his illustrations, Kant appears to suggest we determine a greater degree through the successive composition of lesser ones. Wolff ${ }^{3}$ and Guyer ${ }^{4}$ assert that Kant hereby violates his own precept of instantaneous apprehension of intensive magnitude. Third, many commentators ${ }^{5}$ consider Kant's continuity thesis to be only empirically possible, while Jankowiak regards it as a priori but contingently true. ${ }^{6}$

By solving the above difficulties, this paper claims that Kant's argument for the PAP is tenable in itself and coherent with his philosophy in general. Section II presents Kant's notion of intensive magnitudes and its connection to degrees of consciousness, which is discussed by Buroker ${ }^{7}$ and Zinkin. ${ }^{8}$ The remaining three sections deal with the three difficulties, respectively.

Section III shows that Kant convincingly grounds the PAP in the qualitative categories and their schemata. Some commentators ${ }^{9}$ refer the category of "limitation" to a certain degree that is limited by nothingness and higher degrees. However, in view of Kant's account of negative and infinite judgments (A71/B97-A72/B97), I argue that the schema of "limitation" presents an infinite

${ }^{2}$ For example, Norman Kemp Smith, A Commentary to Kant's 'Critique of Pure Reason,' 2nd ed. (Atlantic Highlands, NJ: Humanities Press, 1962) 352; Thomas Kaehao Swing, Kant's Transcendental Logic (New Haven, CT: Yale UP, 1969) 70-71.

3 Robert Paul Wolff, Kant's Theory of Mental Activity: A Commentary on the Transcendental Analytic of the Critique of Pure Reason (Cambridge, MA: Harvard UP, 1969) 236.

${ }^{4}$ Paul Guyer, Kant and the Claims of Knowledge (Cambridge: Cambridge UP, 1987) 200.

5 For example, Jonathan Bennett, Kant's Analytic (Cambridge: Cambridge UP, 1966) 172; Herbert James Paton, Kant's Metaphysic of Experience: A Commentary on the First Half of the Kritik der reinen Vernunft, Vol. 2 (London: George Allen \& Unwin Ltd., 1970) 142.

6 Tim Jankowiak, "Kant's Argument for the Principle of Intensive Magnitudes," Kantian Review 18 (2013): 387-412, at 395-96.

7 Jill Vance Buroker, Kant's Critique of Pure Reason: An Introduction (Cambridge: Cambridge UP, 2006) 155.

${ }^{8}$ Melissa Zinkin, "Kant on Negative Magnitudes," Kant-Studien 103 (2012): 397-414.

9 For example, Anneliese Maier, Kants Qualitätskategorien (Kantstudien Ergänzungsheft 65) (Berlin, Germany: Pan-Verlag Kurt Metzner, 1930) 55; Abhaya C. Nayak and Eric Sotnak, "Kant on the Impossibility of the 'Soft Sciences,"” Philosophy and Phenomenological Research 55 (1995) 133-151, at 136; Georges Dicker, Kant's Theory of Knowledge: An Analytical Introduction (New York: Oxford UP, 2004) 72; Eric Watkins, "The System of Principles," The Cambridge Companion to Kant's Critique of Pure Reason, ed. Paul Guyer (Cambridge: Cambridge UP, 2010) $151-67$, at 155 . 
sphere of possible degrees, according to which we anticipate a priori that every sensation must instantiate some degree.

In Section IV, following Walker ${ }^{10}$ and Warren ${ }^{11}$ I hold that intensive magnitudes are ordinal. On my reading, cardinal magnitudes can nevertheless constitute an ordinal sequence from the small to the great, such that we can determine degrees by measuring the extensive magnitudes of their corresponding appearances. This enables our understanding of Kant's otherwise problematic examples of sunlight (A178/B220), of candles (MV 28: 424-425), and of warmth (R5663, 18: 322).

Section V distinguishes between what I call the categorical and the empirical notions of continuity. Based on the qualitative categories, the PAP enables the mind to cognize a priori a continuous nexus of possible degrees; but we can only assume a continuous nexus of empirically given sensations that would instantiate all the possible degrees. Against the prevailing reading, ${ }^{12}$ I argue that Kant cannot and does not intend to prove the empirical continuity of alterations in appearances. On the contrary, he calls continuity in nature a "mere idea" (A661/B689), which has no determinative but an "excellent and indispensably necessary regulative use" in directing the understanding to a "goal" (A644/B672).

\section{INTENSIVE MAGNITUDES AND DEGREES OF CONSCIOUSNESS}

Kant begins the PAP section by drawing a correspondence between the real of appearance and sensation of perception as follows:

Perception is empirical consciousness, i.e., one in which there is at the same time sensation. Appearances, as objects of perception, are not pure (merely formal) intuitions, like space and time [...] They therefore also contain in addition to the intuition the materials for some object in general [...] i.e., the real of the sensation, as merely subjective representation, by which one can only be conscious that the subject is affected, and which one relates to an object in general. (B207-208)

For Kant, an appearance is an "undetermined object of an empirical intuition" (A20/B34), while a perception is an appearance "combined with consciousness" (A120). Thus we perceive or intuit an appearance through our perception or consciousness of an undetermined empirical object. An appearance is given "by means of sensibility," and its effect in the subject is called "sensation," which corresponds to the appearance's "matter," material, or real (A19/B33-A20/B34);

${ }^{10}$ Ralph C. S. Walker, Kant (Abingdon, UK: Routledge \& Kegan Paul, 1978) 96.

${ }^{11}$ Daniel Warren, Reality and Impenetrability in Kant's Philosophy of Nature (New York: Routledge, 2011) 22.

${ }^{12}$ Smith (1962) 380; Bennett (1966): 180; Béatrice Longuenesse, Kant and the Capacity to Judge: Sensibility and Discursivity in the Transcendental Analytic of the Critique of Pure Reason, trans. Charles T. Wolfe (Princeton, NJ: Princeton UP, 1998) 315. 
in other words, the real is "an object of the sensation" (B207). But a sensation alone does not represent an appearance, for the latter must be intuited as "ordered in certain relations" through "form," which lies in the mind a priori and to be considered separately from the sensation (A20/B34). According to Kant, the pure forms of intuition are space and time: space is the "form of outer sense" (A26/B42), through which we represent objects as outside in different spaces (A23/B38); time is the "form of inner sense" and "determines the relation of representations in our inner state" (A33/B50).

Kant ascribes sensations to the subject and regards empirical intuitions as being "related to the object through sensation" (A20/B34). Therefore, on the one hand, a sensation is a "merely subjective representation" and ordered in an intuition or empirical consciousness according to space and time. On the other hand, just as an intuition represents the object or appearance, a sensation in the subject corresponds to (or rather represents) the real in the object. However, as we shall see, this distinction between the subjective and objective aspects in the representational act, namely, between the representation in the subject and the object to which the representation relates, is not always rigorously observed in Kant's writings.

In a text that immediately follows the previous citation, Kant connects the gradual alternation of reality to the gradual generation of a sensation:

Now from the empirical consciousness to the pure consciousness a gradual alteration is possible, where the real in the former entirely disappears, and a merely formal (a priori) consciousness of the manifold in space and time remains; thus there is also possible a synthesis of the generation of the magnitude of a sensation from its beginning, the pure intuition $=0$, to any arbitrary magnitude. (B208)

Strictly speaking, the real belongs to an appearance that is represented in the empirical consciousness or intuition. On the other hand, the pure consciousness only has the a priori forms of space and time and contains no sensation, such that it represents no real whatsoever. Just as the empirical consciousness may gradually alter to the pure one, the real it represents may "entirely disappear" and alter from its current grade to zero via many indeterminate grades; and the sensation, which corresponds to the real, may also diminish gradually or, in a reverse order, generate gradually.

In view of this, Kant ascribes to sensation an "intensive magnitude," corresponding to which "all objects of perception, insofar as they contain sensation, must be ascribed an intensive magnitude, i.e., a degree of influence on sense" (B208). Strictly speaking, what contains sensations are not "objects of perception" (i.e., "appearances") but rather empirical intuitions or consciousness. Kant here again conflates the subjective and the objective aspects of representation and takes sensation for an object's real. For another instance, Kant writes in 
a note: "All appearance has as intuition its extensive magnitude and as sensation its degree." (R5585, 18: 241) Most prominently, in the first edition of the first Critique Kant formulates the PAP as "In all appearances the sensation [...]" (A166). Nevertheless, Kant corrects this in the second edition and rephrases the PAP as "In all appearances the real, which is an object of the sensation, has intensive magnitude, i.e., a degree" (B207). Anyway, the gist of Kant's reasoning is clear: since sensation represents an appearance's real, the former's intensive magnitude represents the latter's, namely, a "degree of influence on sense." As Jankowiak puts it, "realities in objects have intensive magnitudes because sensations do." 13 Indeed, we cognize degrees of realities by means of degrees of sensations.

A crucial question arises as to why there must be a "gradual alteration" of real or "generation" of sensation's magnitude. In this text Kant seems to state it as a simple matter of fact without any proper justification. Buroker ${ }^{14}$ suggests that a possible answer lies in Kant's account that "consciousness always has a degree, which can always be diminished" (B414). I notice a similar remark in the Prolegomena: "ever smaller degrees can be thought, just as between consciousness and total unconsciousness (psychological darkness) ever smaller degrees occur." (Pro 4: 307) But this approach has two difficulties: first, as Buroker points out, the intensive continuity of consciousness does not prove that of sensations ${ }^{15}$; second, it remains unexplained why consciousness must admit of degrees of clarity in the first place.

I believe Zinkin has the second difficulty in view when she contends: "In attention (and abstraction) the mind acts like a casual power in gradually sharpening its focus on a representation." 16 Zinkin establishes her argument on Kant's theory of empirical concepts' generation through "comparison," "reflection," and "abstraction" (JL 9: 94-95) and on Kant's assertion that "abstraction (i.e., negative attention) [...] is normally to ensure that what remains is that much more clearly represented" (NG 2: 190). Every abstraction is simply the cancelling of certain sensible data, the purpose of which is to ensure that what remains is an even clearer representation.

But I find this approach unviable in two respects: first, a clearer representation does not necessarily have a greater intensive magnitude or a greater degree of "influence on sense." In judging diverse objects, we compare their differences and reflect on their similarities, while these representations bring about an impact

\footnotetext{
13 Jankowiak (2013): 389. See Jankowiak's paper for a more detailed discussion about the connection between sensation sources and sensations themselves.

14 Buroker (2006): 155.

15 Ibid: 161.

16 Zinkin (2012): 410-11.
} 
on inner sense. The abstraction from certain sensible data (i.e., the differences) seems to reduce rather than enhance this impact. Second, for Kant, the PAP is supposed to be a rule of the "objective use" of the qualitative categories (A161/ B200); but as Zinkin recognizes, ${ }^{17}$ the intensive magnitude in her approach does not relate to the categories in the first Critique.

Unfortunately, such a relation remains inexplicit in Kant's discussions of the PAP, and many commentators consider it simply non-existent. For instance, Smith claims that "logical 'quality' and intensive magnitude have nothing in common save the name," rendering Kant's thesis "both obscure in statement, and unconvincing in argument."18 Similarly, Swing states that "none of [Kant's] attempts is however systematic and complete" and "none of his arguments is convincing." 19 Guyer also contends that the PAP "seems to lack any a priori basis, let alone a clear place in Kant's theory of time-determination or even in the official schematism of the categories." ${ }^{20}$ Nevertheless, in the next section I shall show the contrary.

\section{FROM THE QUALITATIVE CATEGORIES TO THE PAP}

To begin with, we should notice that the categories correspond to the logical functions or the "mere form of the understanding" in judgments (A70/B95). For Kant, in terms of quality, the proposition "The soul is mortal" is affirmative; the proposition "The soul is not mortal" is negative, by which we only avoid an error; and the proposition "The soul is non-moral" is infinite, by which we place the soul "within the unlimited domain of undying being" (A72/B97). Therefore, the infinite judgment does not merely deny that the soul is mortal (as the negative judgment does); it also affirms its placement in an "infinite sphere of the possible" which is "limited only to the extent that that which is mortal is separated from it" (A72/B97-A72/B98). ${ }^{21}$

Kant remarks that, while a negative judgment follows "the principio exclusi medii (between $a$ and non $a$ there is no third thing)," an infinite judgment follows the principle of "thoroughgoing determination," which means "an infinite sphere of the determination of all things, namely, of thinghood, i.e., of reality" (R3063

\footnotetext{
17 Ibid: 403.

18 Smith (1962): 352.

19 Swing (1969): 70-71.

${ }^{20}$ Guyer (1987): 204.

${ }^{21}$ Cf., Kant: 'The infinite judgment indicates not merely that a subject is not contained under the sphere of a predicate, but that it lies somewhere in the infinite sphere outside its sphere; consequently this judgment represents the sphere of the predicate as restricted.' (JL 9: 104) However, the pre-Critical Kant thinks differently, as he writes in the 1764 prize essay: 'All true propositions must be either affirmative or negative.' (UD 2: 294). See also DfS 2: 49.
} 
16:638). In other words, while affirmation and negation correspond to the dichotomous states of a certain $a$, an infinite judgment (through the negation of $a$ ) affirms a third element and adds to $a$ the sphere of "all real things except $a$." We would not open this infinite sphere by merely affirming $a$ (i.e., affirming nothing else) or by merely negating it (i.e., affirming nothing whatsoever). Thus the infinite judgment combines the affirmative and the negative.

From the three qualitative logical functions of all possible judgments, Kant derives three qualitative categories, namely "reality," "negation," and "limitation" (A79/B105-A80/B106). While the PAP is the rule of the objective use of qualitative categories, the latter cannot apply to appearances without some mediation. For Kant, insofar as time is the form of inner sense, the mediation must be a "transcendental time-determination" or a "schema," which is the "representation of a general procedure of the imagination for providing a concept with its image" (A138/B177-A140/B179). With regard to the schemata of qualitative categories, ${ }^{22}$ Kant states that the concept of "reality"

in itself indicates a being (in time). Negation is that the concept of which represents a non-being (in time). The opposition of the two thus takes place in the distinction of one and the same time as either a filled or an empty time. (A143/B182)

Kant seems to distinguish the schemata of the categories of "reality" and "negation" in terms of the dichotomy between being and non-being, namely, between filled and empty times. Lütterfelds asks: how can such a synthesis-form of "negation" possibly belong to the qualitative category and exercise its synthesizing power on a given sensible manifold ${ }^{23}$ Lütterfelds regards this question as an "insurmountable difficulty" and in light of Kant's example of nothingness as "a shadow or cold" (A291/B347), he argues that "negation" actually presents "an intensively-lesser sensation" rather than "a non-being in time or an empty time." 24

I find Lütterfelds' question very challenging. We apply a category to appearances through its schema, but to what could we apply the category of "negation," if its schema should mean no real and thus no appearance at all? Kant writes: "Negation as well as the mere form of intuition are, without something real, not objects." (A292/B349) He also denies the possibility of perceiving "the entire absence of the real in sensible intuition" (A172/B214, cf., B207). Therefore, if nothingness were the schema of "negation," then "negation" would not be applicable to appearances and should not be a category at all.

\footnotetext{
22 These schemata, qua "formal and pure" representations (A140/B179), only deal with objects' pure qualities, namely, their degrees of real in pure time.

23 Wilhelm Lütterfelds, Kants Dialektik der Erfahrung: Zur antinomischen Struktur der endlichen Erkenntnis (Meisenheim: Verlag Anton Hain, 1977) 424.

${ }^{24}$ Ibid: 425. Citations from German texts in secondary literature are my translation.
} 
Meanwhile, I disagree with Lütterfelds' reading of "negation" as a lesser sensation; for in that scenario, the distinction between "negation" and "reality" would be quantitative rather than qualitative. Warren considers Kant's account of "negation" as nothingness to be radically different from the traditional conception at the time, according to which "reality and negation were necessarily regarded as heterogeneous." 25 Nevertheless, in light of Kant's notion of negative judgments, I propose an alternative reading as follows.

While an affirmative judgment states "There is a certain being (say, $a$ ) in time," a corresponding negative judgment should state "There is not $a$ in time." By contrast, judgments such as "There is entirely nothing" or "There is something lesser than $a$," however, would be affirmative. Hence, as I see it, the schema of "negation" should be the mere denial of a certain being in time without any affirmation (not even affirmation of nothingness). By this schema, we can perfectly apply the category of "negation" to appearances: the proposition "There is not $a$ in time" denies only this being but not others (say, $b, c$, or $d$ ), such that we do not judge the time as entirely empty (which would be impossible for cognition). My reading is consistent with both Kant's account of negative judgments and the traditional conception. On the other hand, admittedly, Kant does occasionally refer "negation" to nothingness. Now we are ready to examine the central argument in Kant's schematism section:

Now every sensation has a degree or magnitude, through which it can more or less fill the same time, i.e., the inner sense in regard to the same representation of an object, until it ceases in nothingness $(=0=$ negatio $)$. Hence there is a relation and connection between, or rather a transition from reality to negation, that makes every reality representable as a quantum [...] (A143/ B182-A144/B183)

This text is striking in two aspects: first, the above is Kant's very first discussion of "degree or magnitude" and "[intensive] quantum" in the first Critique, even preceding the section officially entitled "Anticipations of Perception." Again, why must every sensation have a degree? Why could it not so happen, as commentators ${ }^{26}$ suggest, that all realities influence the sense to the same extent? In that scenario, we would perceive only reality (for emptiness cannot be perceived) but no degree at all. Certainly we observe various degrees in experience, yet the crucial question remains their a priori necessity. To the readers' disappointment, Kant simply states "every sensation has a degree" as a matter of fact without any justification. Nevertheless, as I shall show, this does not mean Kant cannot provide one.

\footnotetext{
25 Warren (2011): 20.

${ }^{26}$ For example, Walker (1978): 95; Guyer (1987): 204; Otfried Höffe, Kant's Critique of Pure Reason: The Foundation of Modern Philosophy (Dordrecht, Netherlands: Springer, 2009) 203.
} 
Second, as Guyer notes, the schema of "limitation" is somehow "not even mentioned." 27 Commentators come up with two explanations. On the one hand, Maier, who considers the relation between infinite judgments and "limitation" to be "very loose," 28 claims that "limitation" arises from the "determination of qualitative schema in the category of reality." 29 Similarly, Lütterfelds argues that the categorical synthesis of "limitation" is "deprived of its independence" and received in each "bounded gradation," such that Kant restricts the schema of quality to "reality",30; accordingly, we present both "negation" and "limitation" in the schema of "reality." On the other hand, Heinrichs argues to the contrary: "The category of limitation [...] consists rather in a merely conceptual negation (what makes it interesting), rather than in a predicatively categorical alternative of activity." 31 Thus Heinrichs considers "limitation" a form of "negation." But neither approach squares with Kant's "Table of Categories," according to which "limitation" should be a genuine category and clearly distinguished from both "reality" and "negation" (A80/B106). So let me propose an alternative.

As discussed, the infinite judgment stating "There is not- $a$ " (i.e., "There is possibly anything except $a$ ") adds to $a$ an infinite sphere. Following this, I argue that the schema of "limitation" should be an infinite sphere of all possible realities from which a certain reality $a$ is separated. "Limitation" is more than mere "reality," as the latter only affirms a single reality $a^{32}$; but to place a reality in a "bounded gradation," we require a manifold or a sequence of degrees. "Limitation" is also more than mere "negation," as the latter only denies a certain reality and affirms nothing. Both "reality" and "negation" revolve around the dichotomous state of a certain reality and never address other possibilities. By contrast, "limitation" (through the "negation" of a certain $a$ ) reveals another "reality" that is the infinite sphere of all possible realities except $a$. Indeed, just as an infinite judgment combines affirmation and negation, "limitation is nothing other than reality combined with negation" (B111). "Limitation," as the third qualitative category, reveals a third thing that neither "reality" nor "negation" can access on their own terms.

In view of the logical functions of judgments, our capacity of making infinite judgments is necessary. Accordingly, the schematization of "limitation," namely the presentation of an infinite sphere of possible realities in time, is also

${ }^{27}$ Guyer (1987): 173.

${ }^{28}$ Maier (1930): 44.

${ }^{29}$ Ibid: 61 .

${ }^{30}$ Lütterfelds (1977): 425.

${ }^{31}$ Johannes Heinrichs, Die Logik der Vernunftkritik: Kants Kategorienlehre in ihrer aktuellen Bedeutung: eine Einführung (Bern, Switzerland: Francke Verlag, 1986) 200.

${ }^{32}$ Even if this $a$ turns out to be a group of realities, the schema of "reality" does not present it as a manifold as such. 
necessary. When we regard the nothingness (which is only ideal) as the absolute beginning, we order this sphere into a sequence of degrees, in which realities more approximate to nothingness are assigned "lower" degrees. Hence, we can "anticipate experience precisely in what concerns it matter" (A167/B209), that is, "every sensation has a degree or a magnitude"; and so, we prove the PAP. As Paton points out, the word "Anticipation" is "peculiarly appropriate to the Principle" 33 ; for unlike intuitions, sensations are entirely given a posteriori and contain no a priori form. ${ }^{34}$

The above sheds light on Kant's mysterious notion of the "schema of a reality [Schema einer Realität]." 35 For Kant, every reality is

representable as a quantum, and the schema of a reality, as the quantity of something insofar as it fills time, is just this continuous and uniform generation of that quantity in time, as one descends in time from the sensation that has a certain degree to its disappearance or gradually ascends from negation to its magnitude. (A143/B183)

We should carefully distinguish the schema of "a reality" from the schema of "reality." As discussed, the concept of reality "indicates a being (in time)" (A143/B182); thus we schematize "reality" (i.e., a category) as some being standing alone without envisaging any others. By contrast, based on the schema of "limitation," we schematize "a reality" (i.e., "the quantity of something insofar as it fills time") as a being standing in an infinite sphere of possible beings. Put differently, we place the reality in a sequence of infinite possible degrees and represent its degree as variable from the absolutely small to the absolutely great, which facilitates its "continuous and uniform generation," namely, from negation to any magnitude (or vice versa).

On a prevailing interpretation, insofar as the schema of "negation" is nothingness in time, the schema of "limitation" should be a certain being whose degree is limited by nothingness and some higher degree. For instance, Maier proposes: "The reality and negation then would have corresponded to the two statistic

33 Paton (1970): 134.

34 Maier argues that "Kant has also actually though tacitly assumed a formal structure of the content of sensation as such," namely, the "form of apprehension" or "quality" as the "third presentative form beside spatiality and temporality" (Maier (1930): 64). I would not go that far. For Kant, sensibility is the "capacity (receptivity) to acquire representations through way in which we are affected by objects" (A19/B33). On my reading, through sensibility alone we are affected by an object's real and given a sensation, which has no form whatsoever and does not yet have a degree; only then, the understanding applies the qualitative categories to this sensation and ascribes to it a degree. Insofar as the application is necessary, the PAP anticipates that every sensation (once given) must have a degree, but this is not the condition for its givenness.

35 It is noteworthy that elsewhere Kant always writes "schema of magnitude [der Größe]," "schema of substance [der Subtanz]," "schema of possibility [der Möglichkeit]," and so on (A142/B182-A145/ B184). The term "schema of a reality [einer Realität]" is exceptional. 
schemata of time-filling and time-emptiness, the limitation the dynamic schema of successive generation of time-content." ${ }^{36}$ Dicker also writes: "Think of a less intense sensation (and its correlate in the object) as having a lesser, limited degree of reality." ${ }^{37}$ These commentators polarize the schemata of "negation" and of "reality" in a sequence of realities. But two problems arise: first, as Dicker himself recognizes: "What remains very difficult to see is how these concepts, so interpreted, relate to the judgment forms from which Kant claims to extract them." ${ }^{38}$ Second, this approach cannot account for the necessity of intermediate realities and thus the necessity of the alleged "limited degrees." Again, between a certain filled-time and nothingness, why should there be various time-fillings at all? $?^{39}$

By contrast, according to my approach, we present "negation" as the mere denial of some reality and "limitation" as an infinite sphere of degrees, such that "limitation" affirms a multitude of realities through a negative judgment. On my reading, then, Kant convincingly derives the PAP from the qualitative categories in a way consistent with his theory of judgment forms. This analysis enables a deeper understanding of Kant's account of instantaneous apprehension of intensive magnitude.

\section{INSTANTANEOUS APPREHENSION AND ORDINAL MAGNITUDES}

To begin with, let us first examine Kant's account of extensive magnitudes and their successive apprehension.

Kant presents the Principle of Axioms of Intuition as "All intuitions are extensive magnitudes" (B201). An extensive magnitude is that in which "the representation of the parts makes possible the representation of the whole (and therefore necessarily precedes the latter)" (A162/B203); and so, it "can only be cognized through successive synthesis (from part to part) in apprehension" (A163/B204).

The justification for this principle is rooted in the Transcendental Deduction in the first Critique, where Kant describes a threefold synthesis that is essential for our cognition of objects: the mind firstly apprehends a multitude of impressions successively, and then reproduces them in one unity, so as to recognize them under a concept (A99-A110). To apprehend a manifold of impressions as such,

\footnotetext{
36 Maier (1930): 55.

37 Dicker (2004): 72. Similar remarks are made by Paton (1970: 148-49), Nayak and Sotnak (1995): 136, Buroker (2005): 158, and Watkins (2010): 155.

38 Dicker (2004): 72.

39 To solve this problem, one might appeal to identities of perceptions: a perception, qua one identical perception throughout, must change continuously in degrees of intensity. However, this approach would derive the PAP from mere definition (rather than conditions of experience) and thus fail to justify the Principle's a priori necessity.
} 
the imagination must "distinguish the time in the succession of impressions on one another," for otherwise "as contained in one moment no representation can ever be anything other than absolute unity" (A99). Cognition of objects in space also undergoes this threefold synthesis and the distinction of time, for all representations arise as "modifications of the mind" and "belong to inner sense" (A98-A99), whose form is time (A33/B50). Therefore, all objects, in terms of their intuition in space or time, must be extensive magnitudes and cognized through successive apprehension.

By contrast, Kant claims that "sensation in itself is not an objective representation, and in it neither the intuition of space nor that of time is to be encountered, it has, to be sure, no extensive magnitude" (B208). Just as the real is the matter or material in an appearance, a sensation stands for the subjective aspect of an intuition, such that a sensation in itself does not have an intuition's objective aspect (i.e., space and time). Since a sensation has no time to be distinguished, it cannot be represented from part to part as an extensive magnitude. Instead, we anticipate a priori that a sensation (and the real it correlates to) must possess an intensive magnitude or a degree, whose apprehension is "not successive but instantaneous" (A168/B210).

In the section on schematism, Kant also writes: "Since time is only the form of intuition, thus of objects as appearances, that which in these corresponds to the sensation is the transcendental matter of all objects, as things in themselves (thinghood, reality)." (A143/B182) ${ }^{40}$ What corresponds to the sensation is an appearance's real, which in itself has no time or space. The real remains as a thing in itself until it is combined with the form of intuition and represented as the matter in an appearance (i.e., an object of cognition).

Since an object's real has no parts, it cannot influence sense by parts, such that an intensive magnitude (i.e., the degree of influence on sense) must have no parts and cannot be additive or cardinal (i.e., one, two, three, ...). Following Walker, ${ }^{41}$ I claim that an intensive magnitude is ordinal (i.e., first, second, third, ...) and indicative of a position in an order or sequence. We can sensibly estimate a degree (of heat, sound, clarity of consciousness, etc.) as higher than another; but $40^{\circ}$ is not twice as high as $20^{\circ}$, for we cannot divide $40^{\circ}$ into two $20^{\circ} .42$

${ }^{40}$ With my modification of Guyer and Wood's translation "that which corresponds to the sensation in these." The original text reads "was an diesen der Empfindung entspricht."

${ }^{41}$ Walker (1978): 96.

${ }^{42}$ In the same vein, Warren claims: "a property is assigned intensive magnitude if its instances are only ordered as to greater, lesser, or equal; it is assigned extensive magnitude, if addition is defined on its instances as well." (Warren (2011): 22) Buroker also writes: "Intensive properties like temperature are measured on interval scales rather than ratio scales." Buroker (2006): 157. 
We can derive the ordinal-cardinal distinction from distinction in schemata of categories: the schema of "limitation" presents a sphere of infinite possible realities, whose multiplicity is instantaneously revealed through an infinite judgment (rather than through successive division or composition of parts). On this basis, we regard nothingness as the absolute beginning, order the realities into a sequence according to their approximations to nothingness, and thereby ascribe to each reality an ordinal magnitude or a degree. As Kant puts it, we apprehend an intensive magnitude "as a unity," that is, instantaneously, ${ }^{43}$ and represent its "multiplicity" only "through approximation" to zero (A168/B210). The multiplicity consists in the manifold of intermediate degrees between any arbitrary degree and nothingness. By contrast, Kant declares the schema of extensive magnitude to be "number," namely, "a representation that summarizes the successive addition of one (homogeneous) unit to another" (A142/B182). The successive apprehension of parts makes possible the representation of an extensive magnitude as the whole.

Nevertheless, some of Kant's illustrations seem rather puzzling. Most prominently, Kant states that we can "compose and determine a priori, i.e., construct the degree of the sensation of sunlight out of about 200,000 illuminations from the moon" (A178/B221-A179/B221). As Paton points out, this example concerns not the a priori construction of the actual appearance of the sun, but "rules of a mathematical synthesis" of such a construction. ${ }^{44}$ But the problem remains as to how we construct an intensive magnitude (i.e., the degree of the sensation of sunlight) by means of cardinal measurement (i.e., 200,000 illuminations). Let us examine three possible readings, of which, as I shall show, only the third can be tenable.

The first and obvious reading understands the degree of sunlight as comprising 200,000 degrees of moonlight. Put differently, the sunlight is 200,000 times as great as moonlight in terms of intensive magnitude, much like the earth's diameter is 6,371,000 times as great as a meter in terms of extensive magnitude.

The difficulty is how we construct an intensive magnitude in the same way we do an extensive one. We can certainly determine the length of $6,371,000 \mathrm{~m}$ by aggregating the length of $1 \mathrm{~m}$, or determine the latter by dividing the former. But how can we determine sunlight's degree by aggregating the sensation of moonlight? As Wolff points out, in doing so, the representation of moonlight would precede that of sunlight, such that "sunlight would have extensive magnitude."45 Yet Kant explicitly claims that sensations and realities have neither parts nor

\footnotetext{
${ }^{43}$ Cf., Kant: 'as contained in one moment no representation can ever be anything other than absolute unity.' (A99).

${ }^{44}$ Paton (1970): 146.

${ }^{45}$ Wolff (1969): 236.
} 
extensive magnitudes. In view of this, Wolff argues that "Kant has violated his own precept." 46 However, the above is not the only possible reading.

On the second reading, we determine the sunlight's degree by ascribing to it the extensive magnitude of its effects in appearances. Giovanelli states that the measurement of the sunlight "does not require the summing of magnitudes, but rather the equalizing of relations." 47 According to the inverse-square law in photometry, lux $=$ candela: distance ${ }^{2}{ }^{48}$ Suppose two surfaces excite the same degree of brightness, one of which is situated 447 times more distant to us than the other, then we estimate the former's illumination to be 200,000 times as great as the latter's (without "summing" or dividing either magnitude). This reading finds textual evidence in Kant's lecture on metaphysics:

For instance, the illuminative power of a wax candle is intensively greater than that of a tallow candle, for with the first we can read at a distance of 2 feet and with the second only at 1 foot; the former is therefore the ground of a greater effect [ . .] (MV 28: 424-425) ${ }^{49}$

Guyer takes Kant as suggesting measurement of intensive magnitudes "by differences in the extensive magnitude of the effects, for instance the distance."50 Similarly, on Nayak and Sotnak's interpretation, in both the candle and the sunlight examples Kant illustrates how we "cardinally measure a quality" by finding "some quantity which undergoes changes which are correlated with changes in the intensity of the quality in question." ${ }^{51}$ We assign the tallow candle the degree of $1^{\circ}$, the wax candle the degree of $4^{\circ}$, and a candle with which we can read at $n$ feet the degree of $n^{2 \circ}$. Hence, we can determine the sunlight's degree and its ratio to the moonlight by the squares of their illuminative distances (i.e., cardinal and extensive magnitudes). Moreover, Kant notes that one can determine the qualitative magnitude of warmth "in accordance with the effects that it produces, e.g., that it causes a body to expand" (R5663, 18: 322). Apparently Kant refers to a mercury thermometer: we determine the degrees of temperature in terms of how much they cause a mercury column to expand.

\footnotetext{
46 Ibid: 236.

47 Marco Giovanelli, Reality and Negation - Kant's Principle of Anticipations of Perception (Dordrecht, Netherlands: Springer, 2011) 13.

${ }^{48}$ For further interest on Kant's photometrical studies, cf., Giovanelli (2011) 13; Nayak and Sotnak (1995) 140. Giovanelli asserts that "one can double an illumination ... by diminishing the distance by $1 / 4$ without varying the quantity of light" (Reality and Negation, p. 13). This statement is either mistaken or inclusive of a typo. To double an illumination, we should rather diminish the distance to $1 / 4$.

49 Translation of this text is to Guyer (1987): 199-200. I hereby insert the term "intensively [intensiv]," which is somehow missing in Guyer's translation.

50 Guyer (1987): 200.

51 Nayak and Sotnak (1995): 143.
} 
Despite its merits, the second reading encounters the same difficulty as the first. While illuminative distances and column lengths are extensive in space and time, sensations of sunlight and temperature are intensive and have no space or time in themselves. Hence, a distance consists only of distances, a length of lengths; but a sensation does not consist of sensations.

Thus I propose a third reading, which takes Kant's examples to show how we determine a degree according to an ordinal sequence constituted by cardinal magnitudes. The determination presupposes correspondence between a sensation (which is only intensive) and an appearance (which is also extensive and can be divided or aggregated). The correspondence can take two forms.

In the first form, a sensation represents the real in an appearance. While the moon excites a sensation $a$, the aggregate of two moons (as a collective whole) excites another sensation $b$, and the two sensations constitute a sequence. Insofar as $a$ must be more approximate to nothingness $=0$, we ascribe to $a$ the degree of $1^{\circ}$ and to $b$ the degree of $2^{\circ}$, which only indicate their ranks of approximation to $0^{\circ}$ in the sequence. According to Kant, "the very same extensive magnitude of intuition (e.g., an illuminated surface) can excite as great a sensation as an aggregate of many other (less illuminated) surfaces taken together" (A176/B217). Suppose the sun excites as great a sensation as the aggregate of 200,000 moons taken together, the degree of the sensation of sunlight is then $200,000^{\circ}$, which does not contain $1^{\circ}$ as a part, but which indicates this sensation's rank of approximation to $0^{\circ}$ in a sequence of 200,000 possible sensations.

In the second form of correspondence, a sensation is related to an appearance through a causal connection. For instance, with regard to a growing bonfire, we can determine the changing degrees of its warmth according to the expansions of a mercury column it causes. The degrees are not as composite as the lengths; but the former's sequence (ordered in approximation to nothingness) corresponds to the latter's.

In both cases, we determine intensive magnitudes of sensations through measurement of extensive magnitudes of appearances, insofar as the latter can constitute an ordinal sequence from the cardinally small to great. Guyer objects that for Kant to assume a correlation between a sensation's degree and "a number of parts in the cause [i.e., an appearance]" is to "contradict the inference of the Critique, which assumes that if a degree of intensity is assigned to a sensation, only a degree of efficacy can be assigned to the reality which produces it." 52 But on my reading, while the number of parts in an extensive magnitude is cardinal, the degree of an intensive magnitude is ordinal, such that the correlation does not obscure their essential distinction. As I have shown, this distinction is transcendentally grounded in the distinction of the schemata of the quantitative and the

52 Guyer (1987): 200. 
qualitative categories and is as much genuine as the latter. Hence, against Guyer's pessimistic conclusion, ${ }^{53}$ I argue that the correlation does not render the PAP any less an indispensable condition for the use of the logical function of quality.

Therefore, Kant's examples do not "violate" or "contradict" his own precept of instantaneous apprehension of degrees. Further, the ordinal-cardinal distinction between intensive and extensive magnitudes leads to a crucial distinction in their continuity; to be discussed in the next section.

\section{THE CONTINUITY OF INTENSIVE MAGNITUDES}

Kant defines "continuity" of magnitudes in general as their property on account of which "no part of them is the smallest (no part is simple)" (A169/ B211) ${ }^{54}$ For Kant, space and time are continuous, because "space [...] consists only of spaces, time of times" (A169/B211), that is, because they are infinitely divisible into ever smaller spatial or temporal parts. It follows that an extensive magnitude, successively apprehended in the intuition, is also continuous in terms of having no simple part. Presumably, Kant grounds the proof of the continuity of space and time in the Principle of Axioms of Intuition and in the quantitative categories, but I shall not elaborate here.

By contrast, an intensive magnitude, however small, "can still always be diminished" through a "continuous nexus of possible realities" (A169/B211). On my reading, since an intensive magnitude has no part at all, it is neither continuous nor discontinuous in itself. What can be continuous is rather the nexus of intensive magnitudes, which is no other than the sphere of infinite realities presented in the schema of "limitation." The sphere has parts, namely, smaller spheres of realities; and it has no smallest part, because sphere consists only of spheres, which are infinitely divisible into ever smaller spheres. To illustrate, the sphere of $\left(0^{\circ}, 100^{\circ}\right)$ contains a smaller sphere $\left(10^{\circ}, 50^{\circ}\right)$, while the latter further contains an even smaller sphere $\left(20^{\circ}, 40^{\circ}\right)$, and so on and so forth. The spheres are continuous because they contain infinite degrees, although no degree can be divisible or continuous in itself. We may analogize degrees in the sphere to points on a line; we divide not the points but the line into ever smaller sections that always contain infinite points.

${ }^{53}$ Ibid: $200-201$.

${ }^{54}$ As noted by commentators (e.g., Bennett (1966): 176, Michael Friedman, Kant and the Exact Science (Cambridge, MA: Harvard UP, 1992): 60, 71), nowadays mathematicians would call what Kant means by "continuity" as "density." But 1 shall follow Kant's non-technical usage. 
Many commentators take issue with the necessity of the continuous nexus of degrees. For instance, along with Bennett,${ }^{55}$ Swing argues: "That sense properties are capable of quantitative determination can never be given an a priori proof because it is an empirical assertion." ${ }^{.56}$ In the same vein, Paton thinks "Kant is stating only a possibility," a simple matter of fact." ${ }^{58}$ Moreover, on Guyer's reading, the supposition that "any given sort of sensation can come in a continuous variation of intensity even though it actually occurs in an instant" is only justifiable in a way which "conflicts" with the premise that "all sensation is instantaneous." 59 However, these approaches do not square with Kant's notion of the PAP as a necessary principle. To solve this problem, I distinguish between two notions of continuity as follows.

The first is the continuity of a nexus of possible degrees, which, as I have shown, is grounded in the schemata of the qualitative categories. And so, I call this the "categorical" continuity of intensive magnitudes. Now that "Every necessity has a transcendental condition as its ground" (A106), this continuity is necessary a priori rather than empirical or merely possible. For this reason, I reject Jankowiak's claim that, much like the a priori but contingent fact that space and time are forms of human intuition, Kant's continuity thesis is an a priori but "contingent" truth for us. ${ }^{60}$ Meanwhile, I agree with Jankowiak's identification of "to be continuously variable in intensity" with "to be an intensive magnitude." ${ }^{\prime 61}$ The PAP states a priori that every sensation must instantiate some degree in the continuous nexus of possible degrees (but not that every degree must be instantiated in some sensation).

The second notion of continuity refers to a continuous nexus of degrees that are instantiated in given sensations. Differently put, we hereby consider a nexus of sensations whose degrees constitute a continuous nexus. Since sensations are empirical and their continuity cannot be proved a priori, I call this the "empirical" continuity of intensive magnitudes. To synthesize a multitude of sensations (which belong to different intuitions at different moments) would require successive apprehension.

Therefore, when we apprehend a sensation instantaneously, we determine its degree by having the categorical continuity in view, as we place it in a continuous nexus of possible degrees. This representation is not concerned with the

\footnotetext{
55 Bennett (1966): 172.

56 Swing (1969): 139.

57 Paton (1970): 142.

58 Guyer (1987): 204.

59 Ibid: 202-203.

60 Jankowiak (2013): 395-96.

61 Ibid: 395.
} 
empirical continuity, for we are dealing with one sensation rather than a multitude of sensations. As Weldon nicely puts it:

I need not suppose that the $x$ which I recognize as having a temperature of $n^{\circ}$ has itself passed through the continuous series of changes from $0^{\circ}$ to $n^{\circ}$ in order to reach that state, though I must myself envisage such a progression in order to conceive it as having the determinate intensity of $n^{\circ}{ }^{62}$

The envisaged continuous progression would correspond to the categorical continuity, the $x$ 's gradual passing-through of all the possible thermal degrees to the empirical continuity. We cognize a priori a continuous sequence of possible degrees, such that the $x$ must possess a certain degree in its instantaneous apprehension; but we do not cognize a priori a sequence of empirical sensations whose degrees would constitute a continuous nexus and whose apprehension must be successive. This resolves the aforementioned "conflict" proposed by Guyer.

Therefore, when Kant claims that space and time are as much continuous as a nexus of possible realities, he refers to the categorical continuity of extensive and intensive magnitudes. On this basis, Kant writes: "All appearances whatsoever are accordingly continuous magnitudes, either in their intuition, as extensive magnitudes, or in their mere perception (sensation and thus reality), as intensive ones." (A170/B212) On my reading, since Kant is now dealing with appearances, he hereby turns to the empirical continuity of magnitudes. The argument is twofold: (1) every appearance is infinitely divisible in space and time; (2) every nexus of appearances instantiates a continuous nexus of infinite possible degrees. The second argument presupposes the first, for such a nexus of appearances must be continuous in itself and infinitely divisible in space and time.

If we take Kant as stating a matter of fact or necessary truth, then the first argument would conflict with his resolution of the Second Antinomy in the first Critique, which concludes that "how far the transcendental division of an appearance in general may reach is not a matter of experience at all" (A527/B555). Similarly, since the instantiation of a continuous nexus of degrees presupposes a nexus of infinite appearances, the second argument would conflict with Kant's remark on the thesis in the First Antinomy: "The true (transcendental) concept of infinity is that the successive synthesis of unity in the traversal of a quantum can never be completed." (A432/B460) To sum up, we can never complete the successive synthesis of an infinite division or a nexus of infinite appearances, such that we can never cognize the empirical continuity of appearances (either as extensive or as intensive magnitudes).

Therefore, we should take Kant as stating an assumption. Insofar as the categorical continuity grounds the possibility (but not necessity) of the empirical

62 Thomas Dewar Weldon, Kant's Critique of Pure Reason, 2nd ed. (Oxford: Clarendon Press, 1958) 184. 
continuity, we can "accordingly" assume the latter's existence, but we do not judge any appearances determinatively to be continuous. The necessity of infinite degrees does not entail the necessity of their instantiations. This sheds light on Kant's subsequent discussion as follows:

[1] Now if all appearances, considered extensively as well as intensively, are continuous magnitudes, [2] then the proposition that all alteration (transition of a thing from one state into another) is also continuous could be proved here easily and with mathematical self-evidence, [3] if the causality of an alteration in general did not lie entirely beyond the boundaries of a transcendental philosophy and presuppose empirical principles. (A171/B212-A171/B213, with my insertion of sentence numbers)

I divide the text into three sentences. On my reading, the first sentence reiterates the empirical continuity of magnitudes. The "Now if" introduces an assumption that is possibly true; by contrast, grammatically and philosophically, the "if" leading the third sentence refers to an impossible scenario.

The second sentence introduces the continuity of "transition of a thing." Suppose the first sentence's assumption is true, then we can prove this proposition "easily and with mathematical self-evidence" in two steps: (1) Insofar as appearances are intensively continuous, between two given appearances (which instantiate two degrees of reality) there must be a continuous nexus of appearances (which instantiates a continuous nexus of possible degrees), such that the alteration of an appearance's degree of real must be continuous; (2) As Kant points out, the difference between two states in an alteration must possess a degree of real in itself (A208/B254). This is evident in our expressions of "small" and "great" differences. Hence, based on the first step, which proves the continuity of a thing's alteration in degree, we further prove the continuity of a thing's alteration in general, such as in color or sound.

The proposition of things' continuous alteration fits some of our daily experiences, such as the fall of an apple, or the chromatographic variation in a rainbow. But it seems counterintuitive to say that "a lamp goes off continuously" or that "the colors in a zebra crossing vary continuously." Nevertheless, insofar as time and space are continuous, between two instants or points there can be infinite intermediate ones, through which a gradual alteration of state is always possible.

However, the whole proof relies on a mere assumption, namely, the empirical continuity of magnitudes. For this reason, Kant explicitly claims that the proposition is not but only "could be proved here." In the text above, the third sentence suggests that completion of the proof presupposes "empirical principles." A few lines later, Kant explains: "alterability concerns only certain determinations of appearances, about which experience alone can teach us [...]" (A171/B212) In other words, although we can cognize a priori the categorical continuity of 
magnitudes, only experience can "teach us" the empirical continuity of "appearances" and their alteration.

On a prevailing interpretation, ${ }^{63}$ Kant attempts to derive the law of continuous alteration from the continuity of time. Smith considers this inference "inconclusive," for "we may not without special proof assume that what is true of time must be true of the contents of time." ${ }^{, 64}$ Moreover, in line with Guyer, ${ }^{65}$ Longuenesse points out that "the assertion seems impossible to reconcile with Kant's denial."66

As I see it, in view of Kant's resolution of the Second Antinomy, the continuity of space and time does not prove the continuity of appearances in space and time. Besides, even if we assume the latter to be true, the extensive continuity of appearances only conditions but still does not prove their intensive continuity; for it could happen that, while the alteration of a thing's state from $a$ to $b$ traverses infinite moments and points, the state in each moment and point is either $a$ or $b$ but nothing else. But Kant cannot and does not intend to prove the necessity of the empirical continuity; rather, he successfully grounds its possibility in the categorical continuity and the PAP. Therefore, we can rightfully assume continuous transition in all appearances.

Moreover, on my reading, Kant regards this assumption as requisite for cognition. In a later section in the first Critique entitled "On the regulative use of ideas of pure reason," Kant introduces the principle of "continuity of forms," which offers a "continuous transition from every species to every other through a graduated increase of varieties" (A657/B685-A658/B686). Kant claims that this continuity is a "mere idea" which has no determinative use at all (A661/B689); but he also ascribes to it an "excellent and indispensably necessary regulative use," as it directs the understanding to a "certain goal" (A644/B672). In other words, the idea determines not any object of cognition but the operation of our cognitive powers.

Similarly, in the third Critique, the law of continuity in nature ("lex continui in natura") reads: "[Nature] makes no leaps, either in the sequence of its changes or in the juxtaposition of specifically different forms." (KU 5: 182) According to Kant, the law does not say "what happens" or "how things are judged" but rather "how they ought to be judged" (KU 5: 182). We cannot determine whether natural objects are continuous, but we "ought to" judge them to be continuous and unified under a hierarchical system, that is, we can and should approximate the making of such a judgment as closely as possible. This is analogous to Kant's notion of the highest good, which we cannot realize in the sensible world, but which we ought to.

\footnotetext{
${ }^{63}$ For example, Smith (1962): 380; Bennett (1966): 180; Paton (1970): 292; Guyer (1987): 204; Longuenesse (1998): 315-16.

64 Smith (1962): 380.

65 Guyer (1987): 205.

66 Longuenesse (1998): 316.
} 
Thus I disagree with Watkins' interpretation that the law of continuity expresses an "ontological" claim. ${ }^{67}$ As I have shown, the law only assumes continuity in nature but does not assert its necessary existence. On the other hand, this assumption (of something merely possible) is indeed necessary for our cognition. Again, this is analogous to Kant's ethicotheology, according to which we "must assume" the existence of God for the sake of the "practical necessity" of the highest good (KU 5: 450); by contrast, an "ontological" proof for God's existence would have "the least influence on the merely healthy understanding" (KU 5: 475-476).

\section{CONCLUSION}

By solving three prominent difficulties identified by commentators, this paper defends the tenability and coherence of Kant's argument for the Principle of Anticipations of Perception.

First, with reference to Kant's account of qualitative judgments, I contend that the schema of the qualitative category of "limitation" presents an infinite sphere of possible realities in time, according to which we anticipate a priori that every sensation (and thus the real in every appearance) must instantiate a degree. In this way, Kant can convincingly ground the PAP in a transcendental basis.

Second, on my reading, we apprehend sensations instantaneously and represent their degrees as ordinal magnitudes. Nevertheless, we may determine the degrees according to the extensive magnitudes of their corresponding appearances, insofar as the latter constitute an ordinal sequence from the cardinally small to the great. Thus Kant's examples of intensive magnitudes are reconcilable with his precept of their instantaneous apprehension.

Thirdly, I distinguish between the categorical continuity, which we cognize $a$ priori through the PAP, and the empirical continuity, which we must assume but cannot prove. The former grounds the latter's possibility but not its necessity. As I see it, when Kant claims that all appearances are continuous magnitudes whose changes of state are also continuous, he refers to the empirical and merely possible continuity. In both the first and the third Critiques, Kant ascribes to the law of continuity in nature a regulative use, as it determines no object but sets the necessary aim for our cognition. ${ }^{68}$

Institute of Philosophy of the KU Leuven

${ }^{67}$ Eric Watkins, "Kant on Rational Cosmology," Kant and the Sciences, ed. Eric Watkins (New York: Oxford UP, 2001): 70-89, at 81.

${ }^{68}$ I wish to thank Karin de Boer, Di Huang, and the anonymous reviewer for their comments and suggestions on earlier drafts of this paper. 